\title{
Viabilidade de embriões vitrificados oriundos da fertilização in vitro de oócitos de vacas suplementadas com canola
}

\author{
[Viability of vitrified embryos obtained from the in vitro fertilization of oocytes from \\ cows supplemented with canola] \\ M.C.N. Domingues ${ }^{1}$, L.P. Rigolon ${ }^{2} *$, F.L.B. Cavalieri ${ }^{3}$, M.B. Seko ${ }^{3}$, \\ K. Albuquerque ${ }^{4}$, C.G. Zancheta ${ }^{2}$ \\ ${ }^{1}$ Aluna de pós-graduação - Universidade Estadual de Maringá (UEM) - Maringá, PR \\ ${ }^{2}$ Universidade Estadual de Maringá (UEM) - Maringá, PR \\ ${ }^{3}$ Centro de Biotecnologia da Reprodução (Biotec) - Cesumar - Maringá, PR \\ ${ }^{4}$ Médica veterinária autônoma - Maringá, PR
}

\begin{abstract}
RESUMO
Avaliou-se a produção de oócitos e embriões de vacas Nelore in vitro e a resistência à vitrificação. Foram utilizadas 12 vacas Nelore, distribuídas aleatoriamente em dois tratamentos: T1-tratados com canola em grão (2,0kg/animal/dia) e T2-controle. Cada animal foi aspirado quatro vezes para obtenção de óocitos para fecundação in vitro. Os oócitos foram quantificados e classificados em viáveis ou inviáveis. Os zigotos foram cultivados in vitro e, sete dias após, os embriões foram avaliados quanto à qualidade e grau de desenvolvimento e vitrificados em hastes próprias. Na sequência, foram descongelados e cultivados em 6, 12 e 24 horas, observando-se a taxa de expansão e eclosão. Não houve diferenças $(\mathrm{P}>0,05)$ no número total de oócitos viáveis, $\mathrm{T} 1=12,7 \%$ e $\mathrm{T} 2=11,0 \%$, na taxa de clivagem, $\mathrm{T} 1=60,6 \%$ e $\mathrm{T} 2=61,4 \%$, e taxa de blastocistos, T1=23,7\% e T2=27,0\%, em função do tratamento. Também não houve influência na taxa de re-expansão, T1=70,5 e T2=59,6\%, após a vitrificação e descongelamento. Todavia houve diferença $(\mathrm{P}<0,06)$ para a taxa de eclosão, $\mathrm{T} 1=69,2$ e T2=35,7. Conclui-se que a adição de canola na dieta de vacas não alterou a produção de embriões; entretanto, os embriões resultantes de oócitos coletados de vacas alimentadas com canola são mais resistentes à vitrificação.
\end{abstract}

Palavras-chaves: Nelore, ômega-6, ômega-9, criopreservação, embrião

\begin{abstract}
It was evaluated the production of oocytes and embryos from Nellore cows in vitro, as well as its resistance to vitrification, when the animals were supplemented with canola grains. Twelve Nellore cows were randomly divided into two treatments: T1-treated with Canola grains (2.0kg/animal/day) and T2control. Each animal was submitted to other four aspirations, to obtain oocytes for the in vitro fertilization. The oocytes were quantified and classified as viable or not viable. The embryos were cultivated in vitro, seven days after the quality and the level of development of embryos was evaluated and they were vitrified in vitrification straws. Then, the embryos were thawed and grown during 6, 12 and 24 hours, and the rate of expansion and hatching were recorded. There were no differences $(P>$ $0.05)$ in the whole number of viable oocytes $T 1: 12.7 \pm 1.71$ and $T 2: 11.0 \pm 1.77$, cleavage rate $T 1=$ $60.6 \pm 4,72$ and $T 2=61.4 \pm 4.88$ or blastocysts rate $T 1=23,7 \pm 5.12$ and $T 2=27,0 \pm 5.30$ due to the treatment. The treatments did not influence the rate of re-expansion $T 1=70,5 \pm 6.99$ and $T 2: 59.6 \pm 7.09$ after vitrification and thawing. However, there was a significant difference $(P<0.06)$ in the hatching rate $(T 1$ : $69.17 \pm 7.43 ; T 2: 35.66 \pm 6.86)$. Thus, we conclude that supplementation with canola grains did not change embryos production, but the embryos yielded from oocytes of cows fed canola grains are more resistant to vitrification.
\end{abstract}

Keyswords: Nelore, omega 6, omega 9, cryopreservation, embryo

Recebido em 13 de setembro de 2012

Aceito em 30 de julho de 2013

*Autor para correspondência (corresponding author)

E-mail: lprigolon@uem.br 


\section{INTRODUÇÃO}

Diversas pesquisas vêm sendo desenvolvidas a fim de elucidar os fatores associados ao desempenho reprodutivo dos animais, possibilitando a intervenção nos processos biotecnológicos. A nutrição é importante fator na reprodução dos animais, destacando-se o teor de proteína bruta da dieta (Garcia-Bajalil et al.,1994), a quantidade de vitamina A (Shaw et $a l ., 1995)$ e a de energia na dieta (Nolan et al., 1998). Sabe-se que as gorduras na dieta interferem na taxa de gestação, crescimento folicular, concentração de hormônios e produção de embriões (Williams, 1989).

De acordo com Armstrong (1993), existe grande variabilidade na taxa de ovulação e na produção de embriões viáveis. Muller (2003) apontou os benefícios do uso de fontes ricas em ácidos graxos poli-insaturados, como a canola (ácido linoleico n-6), no aumento do número de embriões viáveis. Resultados semelhantes foram encontrados por Capovilla et al. (2006), ao suplementarem ovelhas Santa Inês com Lac $100 ®$ (ácido linoleico n-6), quando também obtiveram maior número de embriões viáveis nas fêmeas suplementadas.

A produção de embriões in vitro ainda apresenta diferenças morfológicas e metabólicas em relação aos produzidos in vivo, gerados pelas condições de cultivo in vivo (Sá et al., 2003). Essas alterações têm tornado os embriões de FIV mais sensíveis à criopreservação que os obtidos in vivo, diminuindo a viabilidade após o descongelamento e a taxa de gestação (Holm et al., 1998). Os embriões bovinos produzidos in vitro, nos estágios iniciais, possuem grande quantidade de gotas lipídicas no interior do citoplasma, atribuída ao soro adicionado aos meios de cultivo (Tominaga et al., 2000). Os blastômeros apresentam-se aumentados, e o espaço perivitelínico, diminuído (Holm et al., 1998). Além disso, possuem citoplasma mais escuro, menor densidade, menor taxa de crescimento e maior sensibilidade térmica (Rizos et al., 2001).

Evidências sugerem que essa maior sensibilidade dos embriões de FIV ao congelamento esteja relacionada a altas taxas de lipídios que eles apresentam. Estudos realizados com zigotos suínos, nos quais foram removidas as gotas lipídicas de seu citoplasma, mostraram maior taxa de sobrevivência pós-descongelamento. Tratamentos similares foram feitos em bovinos, obtendo-se resultados semelhantes (Holm et al., 1998). De acordo com Twagiraumngu et al. (1997), a congelabilidade dos embriões de FIV está relacionada ao meio de cultivo utilizado no processo. Abe et al. (2002) relataram que gotas lipídicas no citoplasma se acumularam em demasia em mórulas e blastocistos quando zigotos foram cultivados em meio com soro. A adição de ácido linoleico conjugado com albumina nos meios de cultivo resultou em embriões mais resistentes ao processo de criopreservação. Essa melhora possivelmente se deve às modificações na composição lipídica da membrana, facilitando a perda de água pela célula (Laowtammathron et al., 2005).

Cavalieri et al. (2005) demonstraram que novilhas que receberam embriões de vacas alimentadas com linhaça apresentaram aumento na taxa de gestação, sugerindo que embriões congelados oriundos de doadoras suplementadas com linhaça em grão podem ser mais resistentes ao processo de criopreservação em relação àqueles que não o foram. Autores observaram uma relação íntima entre os ácidos graxos da membrana plasmática e a susceptibilidade das células de mamíferos ao processo de criopreservação. Imai et al. (1997) adicionaram ácido linoleico no meio de cultivo de embriões bovinos in vitro e observaram aumento de $28 \%$ na taxa de sobrevivência embrionária pósdescongelamento comparado aos embriões que não receberam ácido linoleico no meio de cultivo. Da mesma forma, Van Soom et al. (2001) observaram aumento na resistência dos embriões bovinos ao congelamento alterando o conteúdo de lipídios do meio de cultivo dos embriões.

Este trabalho foi realizado com o objetivo de avaliar o efeito da suplementação de canola em grão sobre a produção de oócitos, fertilização deles em laboratório e resistência dos embriões à vitrificação de vacas Nelore.

\section{MATERIAL E MÉTODOS}

O experimento foi realizado de abril a junho de 2007. Foram utilizadas 12 vacas da raça Nelore, com média de idade de quatro anos, média de $500 \mathrm{~kg}$ de peso e escore corporal três (escala de 1 
a 5). As vacas foram alojadas em piquetes com $150 \mathrm{~m}^{2}$ e separadas em dois tratamentos com seis animais cada: Tratamento $1=$ Controle: dieta com $7,16 \%$ de farelo de soja $(1,93 \%$ de extrato etéreo) e Tratamento 2 = Suplementação com canola: $8 \%$ de canola em grão $+1,95 \%$ de farelo de soja (extrato etéreo 6,68\%). As duas dietas foram compostas por $11 \%$ de proteína bruta. As vacas foram tratadas previamente com Ivermectina 1\% (Ivomec, Merial®), e receberam, durante 15 dias, silagem de milho e concentrado. As dietas (Tab. 1) foram fornecidas na forma de ração total misturada duas vezes ao dia, às $8 \mathrm{~h}$ e às $16 \mathrm{~h}$.

Tabela 1. Composição percentual dos ingredientes das dietas experimentais (\% / base matéria seca)

\begin{tabular}{lcc}
\hline Alimento (\%) & T1-Controle & T2 - Canola \\
\hline Silagem de milho & 60,00 & 60,00 \\
Milho grão moído & 31,72 & 29,95 \\
Farelo de soja & 7,16 & 1,95 \\
Canola em grão & - & 8,00 \\
Sal mineral & 1,13 & 1,10 \\
Total & 100,00 & 100,00 \\
\hline Composição (\%) & & \\
\hline PB & 11,10 & 11,00 \\
NDT & 68,74 & 67,95 \\
FDN & 41,64 & 41,00 \\
EE & 1,93 & 6,68 \\
Ca & 0,42 & 0,43 \\
P & 0,28 & 0,25 \\
\hline PB: prote
\end{tabular}

PB: proteína bruta; NDT: nutrientes digestíveis totais; FDN: fibra detergente neutro; EE: extrato etéreo; cálcio; fósforo.

As análises bromatológicas foram feitas pela empresa Multimix Nutrição Animal Ltda., e a maturação dos oócitos, a FIV e o cultivo e avaliação dos embriões realizaram-se no Centro de Biotecnologia da Reprodução BIOTEC CESUMAR. Decorridos 15 dias de adaptação alimentar, os ovários foram aspirados (OPU) e o conteúdo desprezado, para padronizar as ondas foliculares. Em continuidade, foram realizadas mais quatro aspirações em cada animal, com intervalo de 15 dias, para obtenção de óocitos para fecundação in vitro. Os oócitos foram quantificados e classificados como viáveis ou inviáveis, sendo os viáveis aqueles com presença de cumulus e ooplasma homogêneo, e os inviáveis aqueles desnudos ou picnóticos, heterogêneos e com vesículas apoptóticas.
A maturação foi realizada em TCM199 com sais de Earles, glutamina e $\mathrm{NaHCO}_{3}$, suplementado com $10 \%$ de soro fetal bovino (SFB), $22 \mu \mathrm{g} / \mathrm{mL}$ piruvato, $50 \mu \mathrm{g} / \mathrm{mL}$ de gentamicina, $0,5 \mu \mathrm{g}$ de $\mathrm{FSH} / \mathrm{mL}, \quad 50 \mu \mathrm{g}$ de $\mathrm{LH} / \mathrm{mL}$ e $1 \mu \mathrm{g}$ de estradiol $/ \mathrm{mL}$, mantidos em estufa, a $39^{\circ} \mathrm{C}, 5 \%$ de $\mathrm{CO}_{2}$ em ar com máxima umidade durante 22-24 horas. Os oócitos foram colocados em microgotas de $90 \mu \mathrm{L}$ de meio de maturação coberta por óleo mineral.

A fecundação foi realizada em $100 \mu \mathrm{L}$ de meio TALP suplementado com $10 \mu \mathrm{g} / \mathrm{mL}$ de heparina, $22 \mu \mathrm{L} / \mathrm{mL}$ de piruvato, $50 \mu \mathrm{g} / \mathrm{mL}$ de gentamicina, albumina sérica bovina-BSA (sem ácidos graxos), solução de $\operatorname{PHE}(2 \mu \mathrm{M}$ de penicilina, $1 \mu \mathrm{M}$ de hipotaurina e $0,25 \mu \mathrm{M}$ de epinefrina). $\mathrm{O}$ sêmen de touro Nelore foi descongelado em banho-maria a $35^{\circ} \mathrm{C}$. Para seleção dos espermatozoides móveis e remoção de diluidores e plasma seminal, foi realizada centrifugação em gradiente percoll (90 e 45\%), durante 20 minutos. Utilizaram-se $1 \times 10^{6}$ espermatozoides $/ \mathrm{mL}$, e os oócitos foram transferidos para as microgotas (20 oócitos/gota), onde permaneceram por 15 a 18 horas, a $39^{\circ} \mathrm{C}$, em atmosfera com $5 \%$ de $\mathrm{CO}_{2}$ em ar.

Após a fertilização, os zigotos foram cultivados in vitro, no meio SOF suplementado com SFB, com monocamada de células da granulosa. O cultivo foi realizado por 15 horas pósinseminação, em incubadora, com atmosfera gasosa contendo $20 \% \mathrm{CO}_{2}$ em ar, com máxima umidade.

Decorridas 48 horas, avaliou-se a taxa de clivagem e realizou-se a renovação do meio de cultivo. Nesse período, quando ocorre a clivagem, observam-se embriões com duas, quatro e oito células. Os embriões com duas células apresentam menor probabilidade de chegar ao estádio de blastocisto. Foi realizada outra avaliação no dia sete para verificação das taxas de blastocistos. Em seguida os embriões foram submetidos à técnica de vitrificação. No protocolo de vitrificação, utilizaram-se dois tipos de solução para realizar o procedimento: solução de equilíbrio etilenoglicol $7,5 \%$ e dimetilsulfoxido a 7,5\% e solução de vitrificação etilenoglicol a $15 \%$ associado ao DMSO e à sacarose $0,5 \mathrm{M}$, e meio tamponado (MT). Os embriões permaneceram na solução de equilíbrio por um período de cinco a 10 minutos e logo 
foram transferidos para três gotas de $20 \mu \mathrm{L}$ da solução de vitrificação, onde permaneceram durante 20 segundos em cada uma. Posteriormente foram colocados na haste de vitrificação e mergulhados diretamente no $\mathrm{N}_{2}$ líquido e transferidos para o tambor de armazenamento.

Na sequência, os embriões foram descongelados e posteriormente transferidos para outra placa com solução diluente em temperatura ambiente por três minutos. Depois os embriões foram lavados nos dois poços seguintes, por cinco minutos cada, com solução de lavagem, e, finalmente, colocados em cultura com meio SOF - Nutricell® com atmosfera gasosa contendo 5\% de $\mathrm{CO}_{2}$ em ar, com máxima umidade, avaliando a cada 6, 12 e 24 horas para verificar sua expansão e eclosão.

O delineamento experimental foi inteiramente ao acaso, com dois tratamentos e seis repetições cada, realizando quatro aspirações com um intervalo médio de 15 dias. As características estudadas foram: número de oócitos viáveis, taxa de clivagem e taxa de blastocisto. Após a vitrificação foram avaliadas as taxas de re-expansão e taxa de eclosão. Todas as características foram testadas para verificação da normalidade dos dados e observou-se que todas as características apresentaram distribuição normal.

Para as características NOV, TCL e TBL foi utilizado o seguinte modelo estatístico: $\mathrm{Y}_{\mathrm{ij}}=\mu+$ $t_{i}+e_{i j}$, em que $\mu=$ média; $t_{j}=$ tratamento $i$ (embriões eclodidos do método tradicional e vitrificação); $\quad \mathrm{e}_{\mathrm{ij}}=$ erro associado a cada observação. Para a análise foi usado Software GLIM 4.0 com distribuição binomial (Nelder e Wedderburn, 1972).

\section{RESULTADOS E DISCUSSÃO}

Não houve efeito $(\mathrm{P}>0,05)$ de canola em grão na dieta sobre o número de oócitos viáveis. $\mathrm{O}$ número de oócitos viáveis é de importância fundamental em programas de FIV, pois está relacionado ao número de folículos presentes nos ovários no momento da aspiração folicular. Ryan et al. (1992), Staples et al. (1996) e Thomas et al. (1997) têm mostrado que animais alimentados com dietas ricas em gordura apresentam aumento no número de folículos médios $(5-9 \mathrm{~mm})$ e grandes $(>9,0 \mathrm{~mm})$, podendo aumentar o número de oócitos produzidos; todavia isso não foi observado nos resultados deste experimento.

Não houve efeito da inclusão $(\mathrm{P}>0,05)$ da canola em grão na dieta, na taxa de clivagem e na taxa de blastocisto (Tab. 2). A produção de embriões depende da qualidade do oócito que é aspirado, que não apresentou diferença entre os tratamentos. A produção e a qualidade dos embriões não se alteraram ao se fornecerem dietas com altos teores de gordura em comparação com dietas controles (Cavalieri et al., 2005). No entanto, outros trabalhos mostraram que a inclusão de gordura na dieta aumentou a taxa de gestação em vacas de leite e corte (De Fries et al., 1996; Petit et al., 1998; Ambrose et al., 2006); sendo assim, esse fator positivo parece não estar relacionado com a qualidade do oócito ou do embrião.

Tabela 2. Número de oócitos viáveis (NOV), taxa de clivagem (TCL) e taxa de blastocisto (TBL) de vacas Nelore segundo os tratamentos

\begin{tabular}{lll}
\hline \multirow{2}{*}{ Variável } & & \\
\cline { 2 - 3 } & T2-Canola & T1-Controle \\
\hline NOV & $12,66 \pm 1,71$ & $11,04 \pm 1,77$ \\
TCL $(\%)$ & $60,62 \pm 4,72$ & $61,39 \pm 4,88$ \\
TBL $(\%)$ & $23,69 \pm 5,12$ & $27,04 \pm 5,30$ \\
\hline
\end{tabular}

Outros fatores, como o aumento na concentração de progesterona, modulação da síntese de prostaglandina e aumento do tamanho do folículo ovulatório, também parecem afetar diretamente a taxa de gestação em animais alimentados com gordura na dieta.

Son et al. (1996) verificaram aumento na produção de progesterona nos animais que receberam gordura animal. Também outros autores obtiveram o mesmo resultado ao fornecer gordura na dieta de vacas em lactação (Williams, 1989; Hawkins et al., 1995; Lammoglia, 1997). Mattos et al. (2000) mostraram que a inclusão de gordura rica em omega 3 na dieta pode auxiliar na sobrevivência embrionária, pois manteria o corpo lúteo íntegro, assim como a concentração de progesterona. Essa seria uma das explicações encontradas por Petit et al. (1998) para o aumento da taxa de gestação quando vacas foram alimentadas com linhaça em grão comparada ao Megalac ${ }$. Embora não tenha sido verificado efeito significativo de tratamento sobre o número 
de oócitos viáveis, houve efeito de vaca dentro de tratamento $(\mathrm{P}<0,05)$, o que pode ser explicado pela grande variabilidade individual dos animais quanto à produção de oócitos.

Com relação à taxa de re-expansão dos embriões, não houve efeito de tratamento $(\mathrm{P}>0,05)$ após os procedimentos de vitrificação e descongelação (Tab. 3). A formação da blastocele se dá por meio da atuação da enzima ATPase (sódio e potássio), a qual favorece o acúmulo de sódio na cavidade embrionária, aumentando sua pressão osmótica e permitindo a entrada de líquido na blastocele (Prestes e Landim-Alvarenga, 2006). No entanto, durante a vitrificação, o embrião se compacta devido à saída de líquido e logo após a descongelação ocorre a re-expansão embrionária. Shu et al. (2008) observaram que a taxa de gestação foi maior nos embriões que reexpandiram mais rapidamente após o descongelamento em comparação com aqueles que demoraram a se re-expandir. De acordo com os resultados deste experimento, parece que a utilização de canola em grão na alimentação de vacas da raça Nelore não alterou a re-expansão do blastocisto produzido in vitro.

Tabela 3. Médias e erros-padrão para taxa de expansão (TEP) e taxa de eclosão (TEC) de embriões de vacas da raça Nelore

\begin{tabular}{lcc}
\hline Variável & Canola & Controle \\
\hline Taxa de re-expansão & $70,48 \pm 6,99 \mathrm{a}$ & $59,62 \pm 7,09^{\mathrm{a}}$ \\
Taxa de eclosão & $69,17 \pm 7,43 \mathrm{a}$ & $35,66 \pm 6,86 \mathrm{~b}$ \\
\hline
\end{tabular}

Médias seguidas de letras diferentes, diferem entre si pelo teste $\mathrm{F}(\mathrm{P}<0,06)$.

Todavia, em relação à taxa de eclosão, verificouse que houve efeito $(\mathrm{P}<0,06)$ de tratamentos. As membranas celulares parecem ser o principal local a ser lesado na criopreservação dos embriões. De acordo com Zeron et al. (2002), a fluidez da membrana determina a concentração de lesão a ser causada na mesma durante o congelamento do embrião. Sendo assim, a descoberta de meios que promovam proteção e resistência às membranas plasmáticas são de grande importância para a obtenção de melhores resultados nos processos de congelamento.

Arav et al. (2000) observaram aumento na resistência dos espermatozoides de carneiros, aumentando a quantidade de ácidos graxos poli- insaturados na membrana plasmática dos mesmos, o que sugere relação estreita entre o perfil de ácidos graxos da membrana e a susceptibilidade dos gametas ao congelamento. Imai et al. (1997), ao adicionarem $1 \mathrm{mg} / \mathrm{mL}$ de ácido linoleico no meio de cultivo de embriões, obtiveram aumento de $28 \%$ na taxa de sobrevivência embrionária pós-descongelamento quando comparado aos embriões que não receberam ácido linoleico. Seguindo a mesma linha, Van Soom et al. (2001) também observaram aumento na resistência dos embriões bovinos ao congelamento alterando o nível de lipídios dos meios de cultivo dos embriões. Pereira et al. (2007) adicionaram ácido linoleico conjugado em meios de cultivo de embriões e verificaram que houve uma redução no acúmulo de lipídios nos embriões e um aumento significativo na sobrevivência embrionária ao processo de criopreservação.

A fonte de gordura da dieta pode alterar o perfil de ácidos graxos das membranas plasmáticas das células (Mattos et al., 2000), o que se sustenta pelos dados achados por Albuquerque et al. (2005), que determinaram a concentração de ácidos graxos no líquido folicular de vacas suplementadas com linhaça e canola em grão, e observaram que, para os ácidos graxos da série n-3 e n-6, o tratamento com canola apresentou concentrações mais altas $(18,3 \%$ e $5,3 \%)$ em relação aos tratamentos testemunha $(5,2 \%$ e $1,6 \%)$ e com linhaça $(6,6 \%$ e $0,4 \%)$. Esses resultados têm implicações diretas no processo de criopreservação dos embriões, pois a maior quantidade de ácidos graxos poli-insaturados na membrana plasmática determina maior fluidez da membrana plasmática (Stubbs e Smith, 1984). De acordo com Zeron et al. (2002), essa maior fluidez aumenta a eficiência de troca da água intracelular pelo crioprotetor, favorecendo a proteção do embrião. Esses dados poderiam explicar a maior taxa de eclosão dos embriões oriundos de oócitos das vacas suplementadas com canola, encontrada neste experimento. Isso porque o fornecimento desse grão deve ter alterado o perfil de ácidos graxos da membrana plasmática dos embriões, conferindo à mesma maior fluidez e, portanto, maior resistência às injúrias provocadas pelo processo de vitrificação e descongelamento. 


\section{CONCLUSÕES}

O fornecimento de canola em grão na dieta de vacas Nelore não altera a produção de oócitos viáveis e as taxas de clivagem, blastocisto e reexpansão. Todavia, os embriões de vacas alimentadas com canola em grão apresentaram maiores taxas de eclosão do que aquelas que não o foram.

\section{REFERÊNCIAS}

ABE, H.; OTOI, T.; TACHIKAW, S. Accumulation of cytoplasmic lipid droplets in bovine embryos and cryotolerance of embryos developed in different systems using serum-free or serum-containing media. Mol. Reprod. Dev., v.61, p.57-66, 2002.

ALBUQUERQUE, K.P. Concentração de ácidos graxos no plasma sanguíneo e no líquido folicular de vacas suplementadas com linhaça ou canola em grãos. 2007. 67f. Tese (Doutorado em Zootecnia) Universidade Estadual de Maringá, Maringá,2007.

AMBROSE, D.J.; KASTELIC, J.P.; CORBETT, R. Lower pregnancy losses in lactating dairy cows fed a diet enriched in $\alpha$-linolenic acid. J. Dairy Sci., v.89, p.3066-3074, 2006.

ARAV, A.; PEARL, M.; ZERON, Y. Does lipid profile explain chilling sensitivity and membrane lipids phase transition of spermatozoa and oocytes. Cryo-Letters., v.21, p.179-186, 2000.

ARMSTRONG, D.T. Recent advances in superovulation of cattle. Theriogenology, v.39, p.7-23, 1993.

CAPOVILLA, L.C.T.; RIGOLON, L.P.; CAVALIERI, F.L.B. Superovulação e viabilidade de embriões de ovelhas santa Inês alimentadas com ácidos graxos essenciais. Rev. Cienc. Agrárias e Amb., v.4, p.32-47, 2006

CAVALIERI, F.L.B.; SANTOS, G.T.; PETIT, H. Taxa de gestação de novilhas alimentadas com duas fontes de gordura (Megalac $®$ ou linhaça em grão) na dieta recebendo embriões congelados de vacas leiteiras alimentadas com LAC-100 ou linhaça em grão. Acta Scie. Vet., v.33, p.216, 2005.

DE FRIES, C.A.; NEUENDORFF, D.A.; RANDEL, R.D. Fat supplementation influences postpartum reproductive perfomance in Brahman cows. J. Anim. Sci., v.36, p.864-870, 1996.

GARCIA-BAJALIL， C.M.; STAPLES， C.R.; THATCHER, W.W. Protein intake and development of ovarian follicles and embryos of superovulated noniactating dairy cows. J. Dairy Sci., v.77, p.25372548, 1994.
HAWKINS, D.E.; NISWENDER, K.D.; OSS, G.M. et $a l$. No increase in serum lipids increases luteal lipid content and alters the disappearance rate of progesterone in cows. J. Anim. Sci., v.73, p.541-545, 1995.

HOLM, P.; CALLESEN, H. In vivo versus in vitro produced bovine ova: similarities and differences relevant for practical application. Reprod. Nutr. Dev., v.38, p.579-594, 1998.

IMAI, K.; KOBAYASHI, S.; GOTO, Y. Cryopreservation of bovine embryos obtained by in vitro culture of ivm-ivf oocytes in the presence of linoleic-acid albumin. Theriogenology, v.47, p.347, 1997.

LAMMOGLIA, M.A.; WILLARD, S.T.; HALLFORD, D.M. Effects of dietary fat folicular development and circulating concentration of lipids, insulin, progesterone, estradiol $17 \mathrm{~b}, 13$, 14-dihydro15-keto-prostaglandin $\mathrm{f} 2 \alpha$ and growth hormone in estrus cyclic Brahman cows. J. Anim. Sci., v.75, p.1591-1600, 1997.

LAOWTAMMATHRON, C.; LORTHONGPANICH, C.; KETUDAT-CAIRNS, M. et al. Factors affecting cryosurvival of nuclear-transferred bovine and swamp buffalo blastocysts: effects of hatching stage, linoleic acid-albumin in IVC médium and Ficoll supplementation to vitrification solution. Theriogenology, v.64, p.1185-1196, 2005.

MATTOS, R.; STAPLES, C.R.; THACTHER, W.W. Effects of dietary on reproduction in ruminants. Rev. Reproduction, v.5, p.38-45, 2000.

MULLER, M. Fontes de gordura e flushing no desempenho de novilhas e vacas de corte no pósparto. 2003. 135f. Tese (Doutorado em Zootecnia) Universidade Estadual de Maringá, Maringá.

NELDER,J.A.; WEDDERBURN, R.H.M. Generalized linear models. Journal of the Royal Statistical Society. v.135, p.370-384, 1972.

NOLAN, R.; DUFFY, P.; WADE, M. et al. Effect of quantity and type of diet and frequency of transvaginal ovum aspiration on in-vitro embryo development in heifers. Theriogenology, v.49, p.402, 1998.

PEREIRA, R.M.; BAPTISTA, M.C.; VASQUES, M.I. et al. Cryosurvival of bovine blastocysts is enhanced by culture with trans-10 cis-12 conjugated linoleic acid (10t, 12c CLA). Anim. Reprod. Sci., v.98, p.293301, 2007.

PETIT, H.V.; DEWHURST, J.G.; PROULX, J.G. Milk yield and reproduction of dairy cows fed saturated or unsaturated fat. J. Dairy Sci., v.81, p.302, 1998. 
PRESTES, N.C.; LANDIM-ALVARENGA, F.C. Obstetrícia Veterinária. Rio de Janeiro: Guanabara Koogan, 2006. p.241.

RIZOS, D.; WARD, F.; BOLAND, M.P.; LONERGAN, P. Effect of culture system on the yield and quality of bovine blastocysts as assessed by survival after vitrification. Theriogenology, v.56, p.116, 2001.

RYAN, D.P.; SPOON, R.R.; WILLIAMS, G.L. Ovarian follicular characteristics, embryo recovery, and embryo viability in heifers fed high-fat diets and treated with follicle-stimulating hormone. J. Anim. Sci., v.70, p.3505-3513, 1992.

SÁ, W.F.; VIZCARRA, V.E.L.; FERREIRA, A.M et al. Desenvolvimento pós-fecundação de oócitos bovinos pré-maturados em fluido folicular. Arq. Bras. Med. Vet. Zootec., v.55, p.287-292, 2003.

SHAW, D.W.; FARIN, P.W.; WASHBURN, S.P.; BRITT, J.H. Effect of retinol palmitate on superovulation rate and embryo quality in superovulated cattle. Theriogenology, v.44, p.51-58, 1995.

SHU, Y.; WATT, J.; GEBHARDT, J. et al. Elective single-embryo transfer in frozen blastocyst transfers cycles. Fertil. and Steril., v.90 , p.S205, 2008.

SON, J.; GRANT, R.J.; LARSON, L.L. et al. Effects of tallow and escape protein on lactational and reproductive performance of dairy cows. J. Dairy Sci., v.79, p.822-830, 1996.

STAPLES, C.R.; THATCHER, W.W.; BURKE, J.M. et al. Influence of supplemental fat on reproductive tissues of the dairy cow. J. Dairy Sci., v.79, p.856-871, 1996.
STUBBS, C.D.; SMITH, A.D. The modification of mammalian membrane polyunsaturated fatty acid composition in relation to membrane fluidity and function. Biochim. and Biophisic Acta, v.779, p.89137, 1984.

THOMAS, M.G.; BAO, B.; WILLIAMS, G.L. Dietary fats varying in their fatty acid composition differentially influence growth in cows fed isoenergetic diets. J. Anim. Sci., v.75, p.2512-2519, 1997.

TOMINAGA, K.; HAMADA, Y.; YABUUE, T. et al. Effect of linoleic acid-albumin on post-thaw survival of in vitro-produced bovine embryos at the 16-cell stage. J. Vet. Med. Sci, v.62, p.465-467, 2000.

TWAGIRAUMNGU, H.; MORIN, N.; BORDIGNON, V. et al. Influence of serum in culture system on the production and cryopreservation of in vitro-derived bovine embryos. Theriogenology, v.47, p.356, 1997. (abstract)

VAN SOOM.; MAHMOUDZADEH, A.R.; CHRISTOPHE, A. Silicone oil used in microdrop culture can affect bovine embryonic development and freeability. Rep. in Dom. Anim., v.36, p.169-176, 2001.

WILLIAMS, G.L. Modulation of luteal activity in postpartum beef cows through changes in dietary lipid. J. Anim. Sci., v.67, p.785-793, 1989.

ZERON, Y.; TOMCZAK, M.; CROWE, J. et al. The effect of liposomes on thermotropic membrane phase transitions of bovine spermatozoa and oocytes: implications for reducing chilling sensitivity. $J$. Reprod. Fertil., v.45, p.143-152, 2002. 